\title{
Adult acquired flat foot deformity: The joint-preserving procedures in stage II tibialis posterior tendon dysfunction
}

\author{
PNF Ferrao MBChB(Pret), FCS(SA)Ortho \\ and

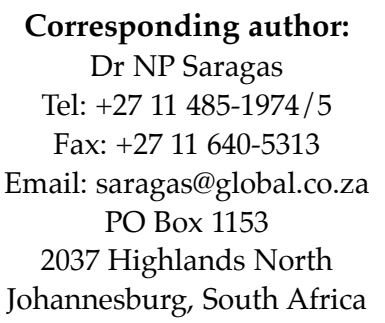

NP Saragas MBBCh(Wits), FCS(SA)Ortho, MMed(Ortho Surg)(Wits)

Netcare Linksfield Orthopaedic Sports \& Rehabilitation Centre (Clinic), Johannesburg

Orthopaedic Department, University of the Witwatersrand, Johannesburg, South Africa

\begin{abstract}
Introduction: The adult acquired flat foot (AAFF) deformity is a chronic debilitating condition commonly associated with dysfunction of the posterior tibial tendon (PTT). It is often missed unless it is associated with a generalised medical condition such as rheumatoid arthritis. Surgical management is indicated when conservative treatment fails. The joint-preserving procedures have evolved over the years and are preferred for the flexible, non-arthritic deformity.

Materials and method: Twenty-two patients were included in this prospective study. The mean age was 59.8 years with the majority being female. The average BMI was 28.7 . The inclusion criterion was symptomatic AAFF deformity due to stage II PTT dysfunction.

Results: Twenty patients were available for follow-up at one year. The mean AOFAS post-operative score of 89 was significantly improved from the pre-operative score of 42 ( $p$ value $=<0.001$ ). Likewise most of the radiographic parameters also improved significantly. The complication rate was very low.

Conclusion: This prospective study shows that the joint-preserving procedures for AAFF deformity due to stage II PTT dysfunction are an effective and preferable option to arthrodesis. There is a low complication rate with high patient satisfaction. A certain amount of training and expertise though, is required.

Level 2 study.
\end{abstract}

Key words: adult acquired flat foot surgery

http:/ / dx.doi.org/10.17159/2309-8309/2016/v15n1a4

\section{Introduction}

The adult acquired flat foot (AAFF) deformity is a chronic and progressive debilitating condition commonly associated with dysfunction of the posterior tibial tendon (PTT).

The pathology is complex and consists not only of PTT insufficiency but also failure of the capsular and ligamentous structures of the foot, leading to a spectrum of deformity with varying degrees of hindfoot valgus, midfoot pronation and forefoot abduction. In later stages arthritic changes can develop in the hindfoot joints. ${ }^{1}$

Ultimately this leads to a painful pes planus deformity and, with pathological changes in the deltoid ligament, associated ankle arthritis.
Initially there may not be a foot deformity at all, but AAFF presents with medial foot pain and decreased function of the affected foot. ${ }^{2}$ Unless the deformity is associated with a generalised medical condition such as rheumatoid arthritis, the diseased tendon is often overlooked and the diagnosis missed. ${ }^{3}$ Kulowski initially described tibialis posterior tendinitis in $1936 .{ }^{4}$ It was not until 1983, however, that Johnson discussed the condition in detail. ${ }^{3}$

\section{Anatomy and biomechanics}

The PTT originates from the posterolateral tibia, posteromedial fibula and interosseous membrane. It courses posterior to the medial malleolus and inserts into the 
navicular tuberosity and the mid-point of the plantar aspect of the tarsus. Blood supply to the tendon is poorest in the area behind the medial malleolus making it the most common site for rupture. ${ }^{5}$

The tibialis posterior tendon is the main supinator of the subtalar joint, an adductor of the midfoot and plantar flexor of the ankle.

It is the primary dynamic stabiliser of the medial longitudinal arch and elevates it with its contraction. The mid- and hindfoot thus lock allowing the triceps surae to effectively push off the forefoot. ${ }^{6}$ The excursion of the PTT is only $1-2 \mathrm{~cm}$ and any 'lengthening' of this tendon has an adverse effect on its function.

\section{Pathophysiology}

Although acute/traumatic rupture of the PTT is an obvious cause of AAFF deformity, the more usual cause is tendinosis (tendon degeneration) from repeated microtrauma. The weakness of this fibrotic PTT subsequently puts a repetitive load on the medial supporting structures, leading to eventual degeneration of the spring and deltoid ligaments.

The consequent shortening of the gastrocnemius further aggravates the flattening of the medial longitudinal arch.

With eversion of the subtalar joint forcing the heel into valgus and abduction at the talonavicular joint, the shortened gastrocnemius muscle ${ }^{1,8}$ further causes subluxation of the talonavicular joint as terminal dorsiflexion of the ankle is achieved by rotation around the talonavicular joint. The navicular thus moves superiorly, laterally and supinates further, rendering the medial column more unstable and collapses the arch. ${ }^{9}$

\section{Epidemiology}

This chronic debilitating condition typically occurs in obese middle-aged females, ${ }^{6,10-13}$ with up to $10 \%$ prevalence in this group $^{14}$ and is known to increase with age, ${ }^{15,16}$ peaking at 55 years of age. ${ }^{8}$ Other risk factors such as diabetes mellitus, ${ }^{15}$ hypertension, ${ }^{15}$ steroid injection around the tendon, ${ }^{17,18}$ and seronegative spondyloarthropathies ${ }^{6,19}$ have been implicated. Mechanical factors must also be at play. ${ }^{20}$
Abnormal forces arising from even mild flat-footedness may result in lifelong greater demands on the PTT..$^{21-24}$

Another possible mechanical cause is overpull of the opposing peroneus brevis muscle. ${ }^{25}$

\section{Classification}

Johnson and Strom first classified PTT dysfunction. ${ }^{26}$ Myerson subsequently added to the classification when degenerative changes are present in the ankle joint or there is involvement of the deltoid ligament. ${ }^{6}$ Johnson and Strom's original classification is based on the condition of the tendon, the position of the hindfoot and flexibility of the deformity. ${ }^{27}$ They identified three stages associated with dysfunction of the PTT, following a progressive course (Table I).

Stage I is characterised by inflammatory changes of the PTT, but neither rupture of the tendon nor deformity. These patients present with tenderness and often oedema over the course of the PTT accompanied by pain and weakness with inversion of the foot, ${ }^{6,28}$ viz. single heel raise test.

In stage II disease patients present with an added flexible deformity, hindfoot valgus, collapse of the medial longitudinal arch and forefoot abduction, viz. 'too many toes' sign ${ }^{3}$ (Figure 1).

A fixed flat foot deformity is present in stage III. ${ }^{26}$

Myerson's stage IV describes deltoid ligament insufficiency, valgus tilt of the talus and ankle arthritis. ${ }^{6}$

The RAM (rearfoot $[R]$, ankle $[A]$, midfoot $[\mathrm{M}]$ ) classification further divides the AAFF deformity into the individual components involved in the disease process (Table II). ${ }^{27}$ An even more 'refined' classification for stage II disease has been adapted from Bluman et al., (Table III).

\section{Investigations}

Plain erect $\mathrm{AP}$, lateral and oblique radiographs of the foot and ankle are necessary to assess the degree of deformity and state of the ankle and hindfoot joints.

MRI, CT scan and ultrasonography are rarely required and only if the diagnosis is obscure. AAFF deformity due to PTT dysfunction can be made clinically.

Table I: Changes associated with various stages of TPT dysfunction ${ }^{26}$

\begin{tabular}{|l|l|l|l|}
\hline \multicolumn{2}{|l}{ Stage 1 } & Stage 2 & \multicolumn{2}{l}{ Stage 3 } \\
\hline TPT condition & $\begin{array}{l}\text { Peritendinitis and/or tendon } \\
\text { degeneration }\end{array}$ & Elongation & Elongation \\
\hline Hindfoot & Mobile, normal alignment & Mobile, valgus position & Fixed, valgus position \\
\hline Pain & Medial: focal, mild to moderate & Medial: along TPT, moderate & Medial: possibly lateral, moderate \\
\hline $\begin{array}{l}\text { 'Too-many-toes' sign with } \\
\text { forefoot abduction }\end{array}$ & Mild weakness & Marked weakness & Marked weakness \\
\hline Pathology & Normal & Positive & Positive \\
\hline Treatment & Synovial proliferation, degeneration & Marked degeneration & Marked degeneration \\
\hline
\end{tabular}




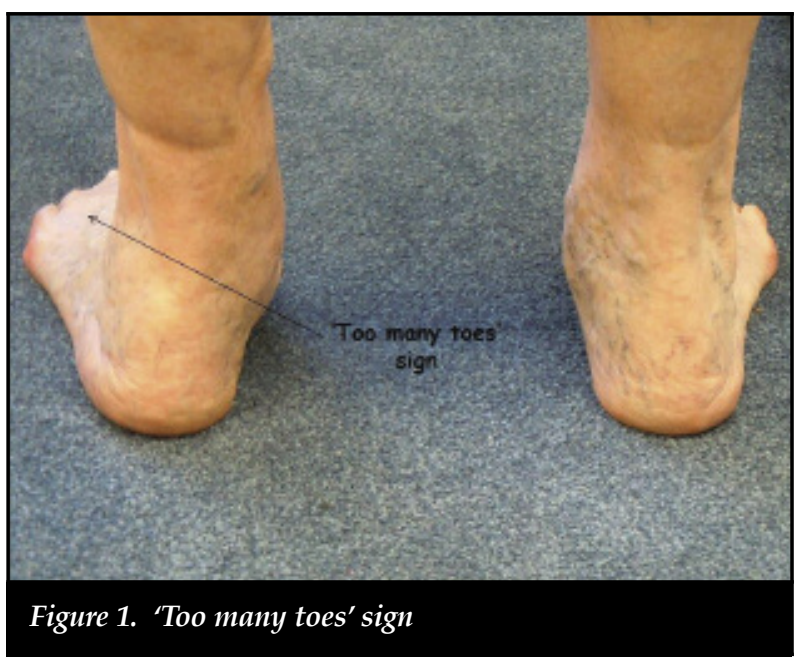

\section{Management}

The aim of treatment is to relieve pain, improve function, restore alignment and arrest the progression of the disease. The management of PTT dysfunction is dictated by the stage of the disease. The Johnson and Strom classification discussed earlier is commonly used to guide management decision-making.

Stage I is the early inflammatory stage. This is ideally managed conservatively. The treatment consists of rest, support and rehabilitation. The patient must refrain from all impact and strenuous activities for at least six weeks. The PTT can be supported with either a custom supportive orthotic or specialised brace (Airlift brace). In severe cases boot or cast immobilisation is required. Rehabilitation is addressed with physiotherapy, consisting of anti-inflammatory modalities, strengthening and proprioception.

\section{Table II: The RAM Classification ${ }^{27}$}

\begin{tabular}{|c|c|c|c|}
\hline \multicolumn{2}{|r|}{ Rearfoot } & Ankle & Midfoot \\
\hline Ia & Tenosynovitis of PTT & Neutral alignment & Neutral alignment \\
\hline $\mathrm{Ib}$ & PTT tendonitis without deformity & Mild valgus $\left(<5^{\circ}\right)$ & Mild flexible midfoot supination \\
\hline IIa & $\begin{array}{l}\text { Flexible planovalgus ( }<40 \% \text { talar } \\
\text { uncoverage, }<30^{\circ} \text { Meary angle, } \\
\text { incongruency angle } 20^{\circ} \text { to } 45^{\circ} \text { ) }\end{array}$ & $\begin{array}{l}\text { Valgus with deltoid insufficiency (no } \\
\text { arthritis) }\end{array}$ & $\begin{array}{l}\text { Midfoot supination without } \\
\text { radiographic instability }\end{array}$ \\
\hline $\mathrm{Ilb}$ & $\begin{array}{l}\text { Flexible planovalgus ( }>40 \% \text { talar } \\
\text { uncoverage, }>30^{\circ} \text { Meary angle, } \\
\text { incongruency angle }>45^{\circ} \text { ) }\end{array}$ & $\begin{array}{l}\text { Valgus with deltoid insufficiency } \\
\text { with tibiotalar arthritis }\end{array}$ & $\begin{array}{l}\text { Midfoot supination with midfoot } \\
\text { instability - no arthritis }\end{array}$ \\
\hline IIIa & $\begin{array}{l}\text { Fixed / arthritic planovalgus }(<40 \% \\
\text { talar uncoverage, }<30^{\circ} \text { Meary angle, } \\
\left.\text { incongruency angle } 20^{\circ} \text { to } 45^{\circ}\right)\end{array}$ & $\begin{array}{l}\text { Valgus secondary to bone loss in the } \\
\text { lateral tibial plafond (deltoid normal) }\end{array}$ & $\begin{array}{l}\text { Arthritic changes isolated to medial } \\
\text { column (navicular-medial cuneiform } \\
\text { or first TMT joints) }\end{array}$ \\
\hline IIIb & $\begin{array}{l}\text { Fixed / arthritic planovalgus ( }>40 \% \\
\text { talar uncoverage, }>30^{\circ} \text { Meary angle, } \\
\text { incongruency angle }>45^{\circ} \text { ) - not } \\
\text { correctable through triple arthrodesis }\end{array}$ & $\begin{array}{l}\text { Valgus secondary to bone loss in the } \\
\text { lateral tibial plafond and with } \\
\text { deltoid insufficiency }\end{array}$ & $\begin{array}{l}\text { Medial and middle column midfoot } \\
\text { arthritic changes (usually with } \\
\text { supination and/or abduction of the } \\
\text { midfoot) }\end{array}$ \\
\hline
\end{tabular}

Table III: 'Refined' classification for stage II disease ${ }^{8,29}$

\begin{tabular}{|c|c|c|c|}
\hline Stage & Subdivision & Pathology & Recommendation \\
\hline \multirow{9}{*}{ II } & \multirow{3}{*}{ A } & Flexible hindfoot valgus with & \\
\hline & & Flexible forefoot varus & $\begin{array}{l}\text { Medial posting/brace }+ \text { tendoachilles lengthening } \\
\text { if forefoot varus corrects only in equinus }\end{array}$ \\
\hline & & Fixed forefoot varus & $\begin{array}{l}\text { MDCO (arthroereisis) + FDL transfer + } \\
\text { Cotton osteotomy if fixed forefoot varus }\end{array}$ \\
\hline & \multirow{3}{*}{ B } & $\begin{array}{l}\text { Forefoot abduction (at transverse tarsal, } \\
\text { first TMT joint or both }\end{array}$ & \\
\hline & & Talar head uncovering $<40 \%$ & $\mathrm{MDCO}+$ FDL transfer \\
\hline & & Talar head uncovering $>40 \%$ & $\begin{array}{l}\text { FDL transfer + lateral column lengthening } \pm \\
\text { DCO/arthroereisis (if residual heel valgus) }\end{array}$ \\
\hline & \multirow{3}{*}{$\mathrm{C}$} & Medial ray instability & \\
\hline & & $\begin{array}{l}\text { Persistent forefoot varus after } \\
\text { correction of heel }\end{array}$ & \\
\hline & & $\begin{array}{l}\text { Talonavicular/naviculocuneiform/ } \\
\text { first TMT joint level }\end{array}$ & Fusion of appropriate joint if arthritic/Cotton osteotomy \\
\hline
\end{tabular}

Abbreviations: Cotton osteotomy: opening wedge medial cuneiform osteotomy; FDL: flexor digitorum longus; TMT: tarsometatarsal 
Cortisone injections play no role in the management of this disease. If symptoms are refractory to conservative management for three months, surgical intervention is indicated. If the tendon integrity is maintained a tenosynovectomy is performed.

Stage II by definition is a flexible flat foot deformity with intrinsic tendon pathology. These patients are candidates for the so-called 'joint sparing (preserving)' procedures. This is the group of patients this study investigated. In the presence of a positive Silfverskiöld test a gastrocnemius recession needs to be performed. Stage IIA is managed with a medial displacement calcaneal osteotomy, spring ligament plication and flexor digitorium longus (FDL) tendon transfer. In stage IIB the above is done with the addition of a lateral column lengthening to address the severe forefoot abduction. There is a high risk of the spring ligament being completely ruptured requiring reconstruction (this type of procedure is beyond the scope of this article). Stage IIC is the patient with fixed compensatory forefoot supination. This is corrected with a dorsal opening wedge osteotomy of the medial cuneiform (Cotton osteotomy). Stage II will be discussed in detail.

When the flat foot deformity becomes rigid and/or hindfoot arthritis develops, it gets classified as stage III. The only surgical option at this stage is a triple arthrodesis of the hindfoot joints with correction of the deformity.

Stage IV with ankle arthritis is best treated with a pantalar fusion. Stage IV with deltoid insufficiency can be managed with a deltoid reconstruction. A couple of techniques have been described with limited results in the literature. Therefore a fusion of the ankle is still commonly performed.

Failure of conservative treatment is the commonest indication to consider surgery.

Surgery is indicated in patients who have failed nonoperative management for three months or more. ${ }^{30}$

\section{Materials and method}

The purpose of this prospective study is to report on the effectiveness of treating stage II PTT dysfunction by jointpreserving procedures. Non-surgical, surgical management of the other stages and the merits of certain operative procedures is beyond the scope of this article.

Between March 2013 and July 2014, 22 patients (16 female and six male) met the inclusion criteria. The inclusion criteria were symptomatic AAFF deformity due to stage II PTT dysfunction not responding to at least three months' conservative treatment.

All patients had weight bearing $\mathrm{AP}$, lateral and oblique radiographs of the involved foot and ankle.

As the disease is characterised by medial longitudinal arch depression, talar depression and abduction of the forefoot, the appropriate radiographic parameters were measured as follows: ${ }^{31,32}$ talonavicular coverage angle (TNCA); percentage talar head uncoverage(\% $\%$ TU); talo-first metatarsal angle (Meary's)(TFMA); lateral talocalcaneal angle (LTCA); calcaneal pitch angle (CPA) and medial cuneiform to floor distance (MCFD) (Figure 2).

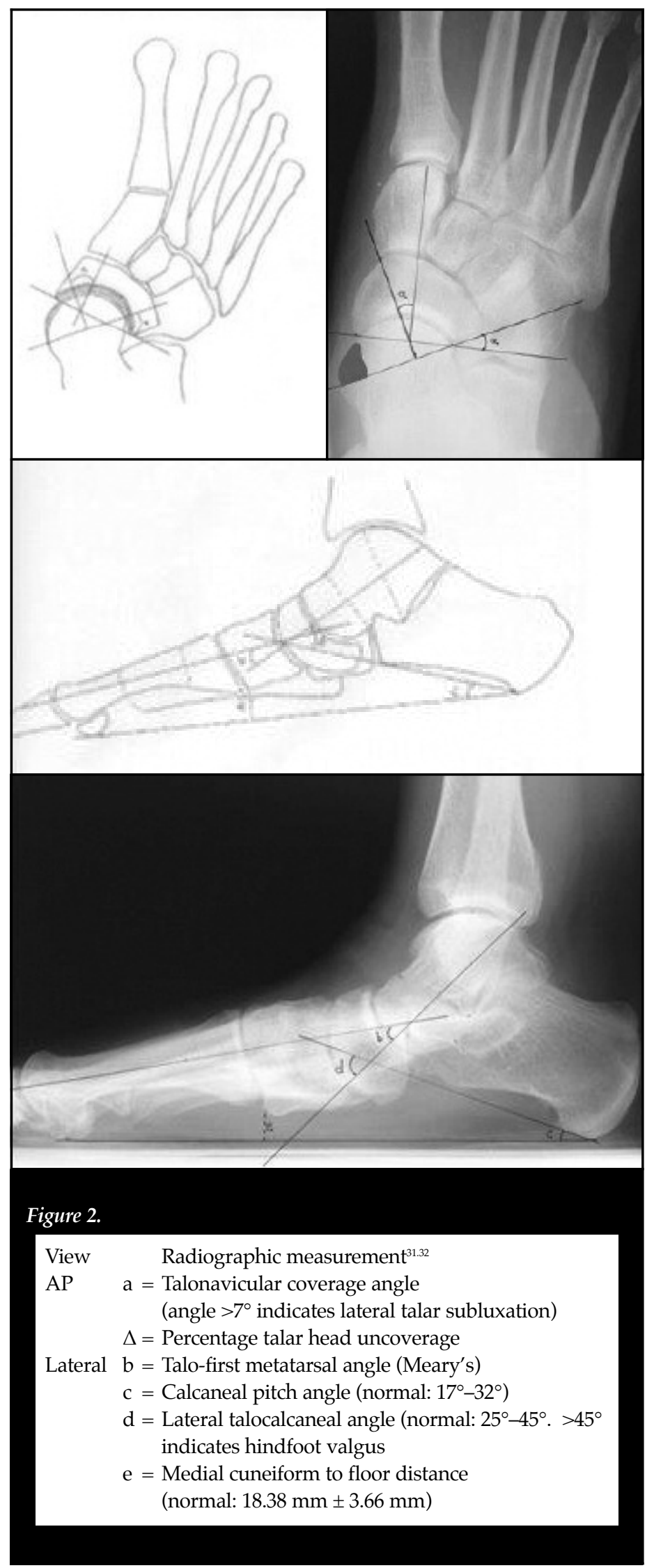


Ten patients had a pre-operative ultrasound, which showed varying degrees of PTT degeneration (moderate to complete rupture).

All patients signed an informed consent form.

\section{Surgical technique}

The patient is placed supine on the table with a bolster under the ipsilateral buttock as the calcaneal osteotomies are performed first. The procedure is performed under general anaesthesia with a regional block. A thigh tourniquet is used.

\section{Medial displacement calcaneal osteotomy}

A $5 \mathrm{~cm}$ incision is made posterior to the peroneal tendons from the superior border of the calcaneal tuberosity distally to the inferior border of the tuberosity anterior to the inferior calcaneal spur (Figure 3). The incision is parallel to the axis of the fibula and curves slightly anteriorly at its distal end.

Particular attention must be paid to the sural nerve branches, the peroneal tendons and the subtalar joint.

It is prudent to use intra-operative fluoroscopy initially to identify the landmarks and the direction of the osteotomy. We have found that the larger the osteotomised calcaneal segment, the easier it is to displace it. Once the osteotomy is complete (initially with a power saw and finished with fine osteotomes), two lamina spreaders are inserted in the osteotomy to prise it open and tear the medial periosteum (Figure 4).

The calcaneal tuberosity is shifted medially by approximately $8-10 \mathrm{~mm}$.

The osteotomy is fixed with either a $7.5 \mathrm{~mm}$ compression screw inserted from the posterior aspect of the tuberosity under image control or alternatively an Edgelock ${ }^{\mathrm{TM}}$ plate (Tornier SAS, US, Minneapolis, Minnesota). The shelf of the anterior fragment created from the shift is 'crushed' with a punch so that the cortical continuity is maintained and no raw bony surface is left to cause adhesions of the soft tissue.

\section{Lateral column lengthening}

If there is over $40 \%$ uncoverage of the talar head in the preoperative radiographs, a lateral column lengthening is performed.

A second horizontal $4 \mathrm{~cm}$ incision is made, extending from the calcaneo-cuboid (c-c) joint, posteriorly across the neck. The c-c joint is identified with a hypodermic needle. The osteotomy is carried out approximately $15 \mathrm{~mm}$ from the c-c joint and extends between the anterior and middle facets of the calcaneus.

The osteotomy is then distracted with either pin distractors or a lamina spreader, until the talus is adequately covered by the navicular as checked under image (Figure 5). Avoid overcorrection. Once the desired distraction is achieved, the osteotomy is filled with a tricortical graft and staple or a MaxLock Extreme ${ }^{\mathrm{TM}}$ plate (Tornier SAS, US, Minneapolis, Minnesota) fixation (Figure 6).

We avoid c-c joint fusion.
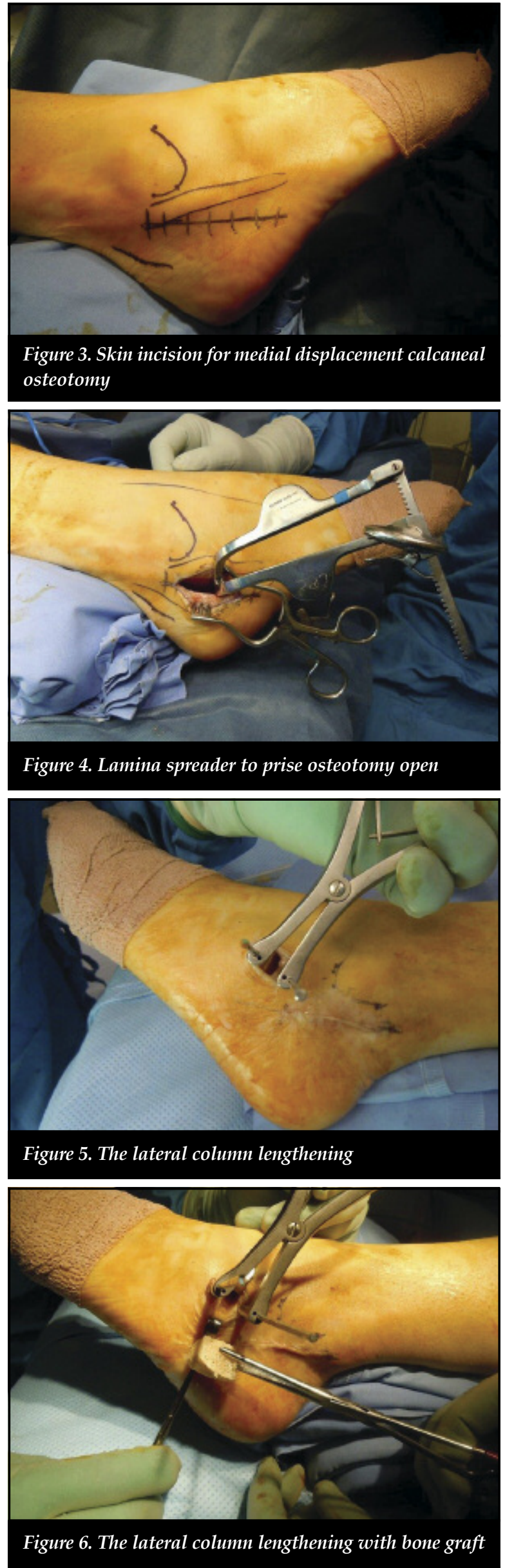


\section{Gastrocnemius recession}

The bolster is now removed from under the patient, allowing the leg to externally rotate.

The gastrocnemius recession is indicated if the Silfverskiöld test is positive pre-operatively.

A small longitudinal incision is made posteromedially in the calf, approximately $15 \mathrm{~cm}$ from the Achilles tendon insertion.

The fascia of the gastrocnemius tendon is identified and dissected off the tendinous portion. The tendinous portion is horizontally transected starting from its lateral edge, extending medially under direct vision.

Be aware of the sural nerve laterally!

\section{Flexor digitorum longus (FDL) tendon transfer}

An $8 \mathrm{~cm}$ curved incision is made over the PTT, extending from the medial malleolus to the naviculo-cuneiform joint (Figure 7). The incision may extend more proximally, depending on the amount of PTT damage that will have to be debrided / resected.

Once the sheath of the PTT is opened, the tendon is inspected and debrided / repaired / excised (Figure 8). Peel off the PTT and roughen the insertion site on the navicular tuberosity by using a rongeur. The spring ligament is then inspected. It is identified as the tissue deep to the PTT attachment. It extends from the navicular tuberosity to the sustentaculum. The identification is easy when there is an obvious tear present (Figure 9). More often it is attenuated.

Immediately behind and slightly posterior, at level of the medial malleolus, the sheath of the FDL is identified and opened (Figure 10). The FDL is then delivered from its sheath and tugged with a tendon hook to make sure that the lesser toes move.

A four-strand bioabsorable anchor, Suturetak ${ }^{\circledR 2}$ fiberwire $^{\circledast}$ and two Tigerwire sutures ${ }^{\circledast}$ (Arthrex, Naples, Florida) is placed into the navicular tuberosity. The two strands of the anchor are used to repair/imbricate the spring ligament. This is secured first before the FDL (Figure 11).

The other two strands are used to secure the transferred FDL with the foot in full inversion and equinus (Figure 12) (if there is no gastrocnemius recession), otherwise in neutral dorsiflexion under tension.

If there is any good quality remainder of the PTT, this is attached to the FDL to further reinforce the transfer. Do not leave any damaged PTT behind as it may be a pain generator.

The distal portion of the transferred FDL need not be transected as it will ultimately stretch out and the lesser toe movement is not compromised.

Once all the repairs/transfers are secure, the PTT sheath is repaired with absorbable suture, as is the rest of the wound. The foot is maintained in full inversion and equinus/neutral dorsiflexion depending on whether a gastrocnemius recession was performed or not.

A below-knee $(\mathrm{B} / \mathrm{K})$ non-weight bearing $(\mathrm{NWB})$ cast is applied (Figure 13).
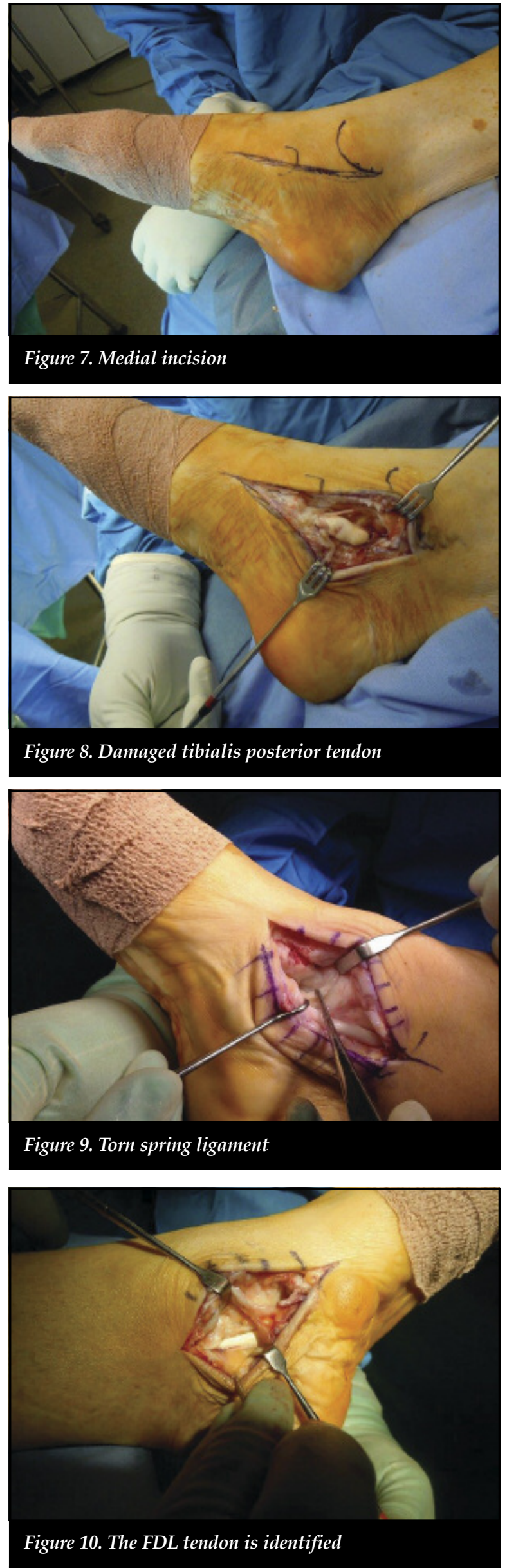


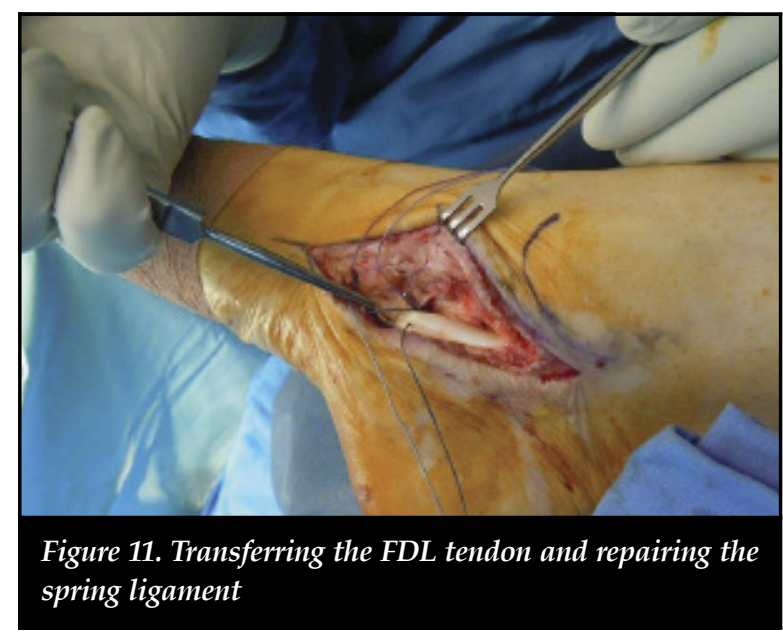

Spring ligament reconstruction is beyond the scope of this article.

\section{Post-operative protocol}

The patient remains in the NWB cast for six weeks. Radiographs are taken once the cast is removed. The patient is then placed in a 'moon boot' allowing progressive weight bearing to full weight bearing over a period of six weeks while receiving physiotherapy.

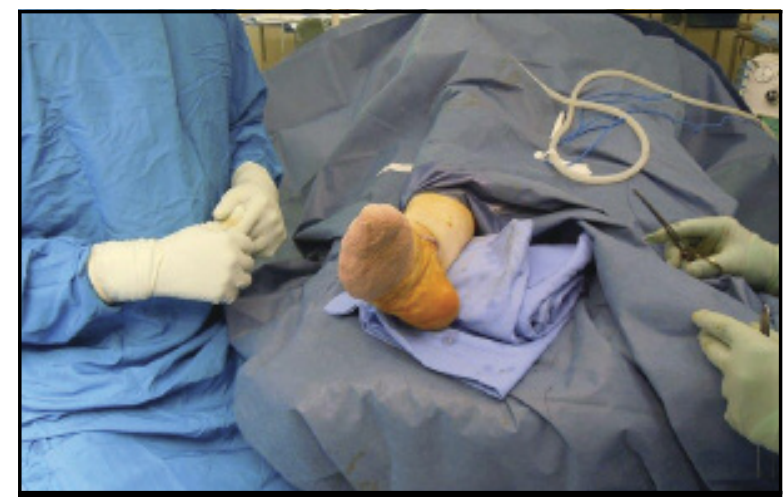

Figure 12. The foot in full inversion and equinus

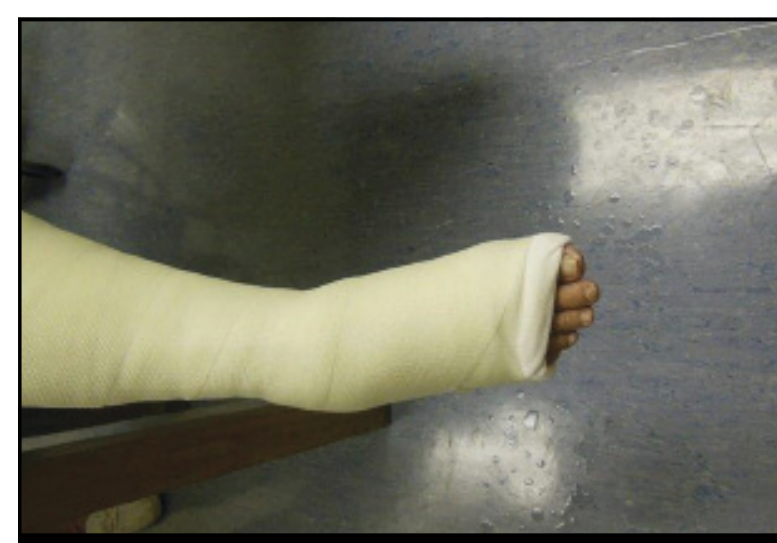

Figure 13. Immobilise the foot in equinus and inversion
The physiotherapy/biokinetics continues until full strength and proprioception is achieved. The patient is advised that the average time to maximum improvement is 9-12 months.

Active/passive eversion beyond neutral is avoided for at least three months.

Of note, the patient is covered with oral anticoagulants for six weeks until the cast is removed. There is a high risk of deep vein thrombosis (DVT) with this type of surgery

together with immobilisation and NWB status..$^{33}$

\section{Results}

Twenty patients were available for follow-up. There were 15 females and five males, with an average age of 59.8 years (range 49 to 70 years). The patients were examined and radiographs taken at least one year post-operatively. All radiographic measurements (pre- and final post-operative radiographs) were reviewed by the senior author (NPS) so as to eliminate inter-observer error. The AOFAS questionnaire was completed by both authors.

\section{Statistical analysis}

The data were analysed using STATA 13 statistical software (STATA Corporation,

College Station, TX USA). The following variables were included in the analysis:

MCFD, TFMA, CPA, TNCA, LTCA, \%TU and AOFAS score. Exploratory data analysis included histograms, box graphs, mean (standard deviation) and range of continuous variables. The paired sample t-test was used to determine if there was a statistically significant difference in mean values recorded pre- and post-surgery for each measure; statistical tests were two-sided at $\alpha=0.05$.

The average pre-operative AOFAS score was 42 (range 17 to 65 ). The average post-operative score was 89 (range 50 to 100 ). The improvement was statistically significant ( $\mathrm{p}$ value $=<0.001$ ). The average BMI was 28.7 (range 19 to 53$)$.

The demographics in terms of BMI, age and gender of our cohort of patients were in keeping with the reported literature.

The radiographic improvement was as follows:

The average pre-operative medial cuneiform to floor distance was $12.4 \mathrm{~mm}$ (range 0 to 20) and the average post-operative score was $16.3 \mathrm{~mm}$ (range 6 to 24), ( $\mathrm{p}$ value $=<0.001)$

The average pre-operative talo first metatarsal angle (Meary's) was $-20.5^{\circ}$ (range -35 to -2 ) and postoperatively was $-12.3^{\circ}$ (range -32 to 6$)$, $(\mathrm{p}$ value $=0.003$ ).

The average pre-operative calcaneal pitch angle was $17.2^{\circ}$ (range 10 to 26 ) and post-operatively was $18^{\circ}$ (range 8 to 23$)$, ( $\mathrm{p}$ value $=0.288$ )

The average pre-operative talo navicular coverage angle was $27^{\circ}$ (range 6 to 39 ) and post-operatively was $18.4^{\circ}$ (range 4 to 43$)$, $(\mathrm{p}$ value $=0.002)$. 
The average lateral talo calcaneal angle was $50^{\circ}$ (range 35 to 62 ) and post-operatively was $47^{\circ}$ (range 38 to 59), ( $\mathrm{p}$ value $=0.155)$.

The average pre-operative percentage talar head uncoverage was $35.6 \%$ (range 15 to 50 ) and post-operatively was $26.2 \%$ (range 10 to 45$)$, (p value $=<0.001$ ) (Table IV).

For MCFD, TFMA, CPA, TNCA, LTCA and \%TU the data included 16 matched results; for AOFAS score the data included 20 matched results.

There was an increase in the mean values from pre-op to post-op for MCFD, TFMA, CPA and AOFAS score; these results are statistically significant for MCFD, TFMA and AOFAS score, for CPA the difference is slight and not statistically significant.

\section{Table IV: Results: Pre- and post-operative measurements}

\begin{tabular}{|c|c|c|c|c|}
\hline & Measurement & $\begin{array}{c}\text { Pre-operative } \\
\text { Mean (SD) Range }\end{array}$ & $\begin{array}{c}\text { Post-operative } \\
\text { Mean (SD) Range }\end{array}$ & P-value \\
\hline \multirow{3}{*}{$\mathrm{AP}$} & AOFAS score & $\begin{array}{l}42,0(13.3) \\
17 ; 65\end{array}$ & $\begin{array}{c}89,5(12.3) \\
50 ; 100\end{array}$ & $<0.001$ \\
\hline & Talonavicular coverage angle & $\begin{array}{c}26.9(7.9) \\
6 ; 39\end{array}$ & $\begin{array}{l}18.4(11.6) \\
4 ; 43\end{array}$ & 0.002 \\
\hline & Percentage talar head uncoverage & $\begin{array}{c}35.6(7.7) \\
15 ; 50\end{array}$ & $\begin{array}{l}26.2(10.8) \\
10 ; 45\end{array}$ & $<0.001$ \\
\hline \multirow{4}{*}{ Lateral } & Medial cuneiform to floor distance & $\begin{array}{l}12.4(4.7) \\
0 ; 20\end{array}$ & $\begin{array}{l}16.3(4.0) \\
6 ; 24\end{array}$ & $<0.001$ \\
\hline & Talo first metatarsal angle (Meary's) & $\begin{array}{l}-20.5(8.6) \\
-35 ;-2\end{array}$ & $\begin{array}{c}-12.3(11.4) \\
-32 ; 6\end{array}$ & 0.003 \\
\hline & Calcaneal pitch angle & $\begin{array}{c}17.2(4.3) \\
10 ; 26\end{array}$ & $\begin{array}{l}17.9(4.5) \\
8 ; 23\end{array}$ & 0.288 \\
\hline & Lateral talo calcaneal angle & $\begin{array}{c}50.2(6.7) \\
35 ; 62\end{array}$ & $\begin{array}{c}47.2(6.3) \\
38 ; 59\end{array}$ & 0.155 \\
\hline
\end{tabular}

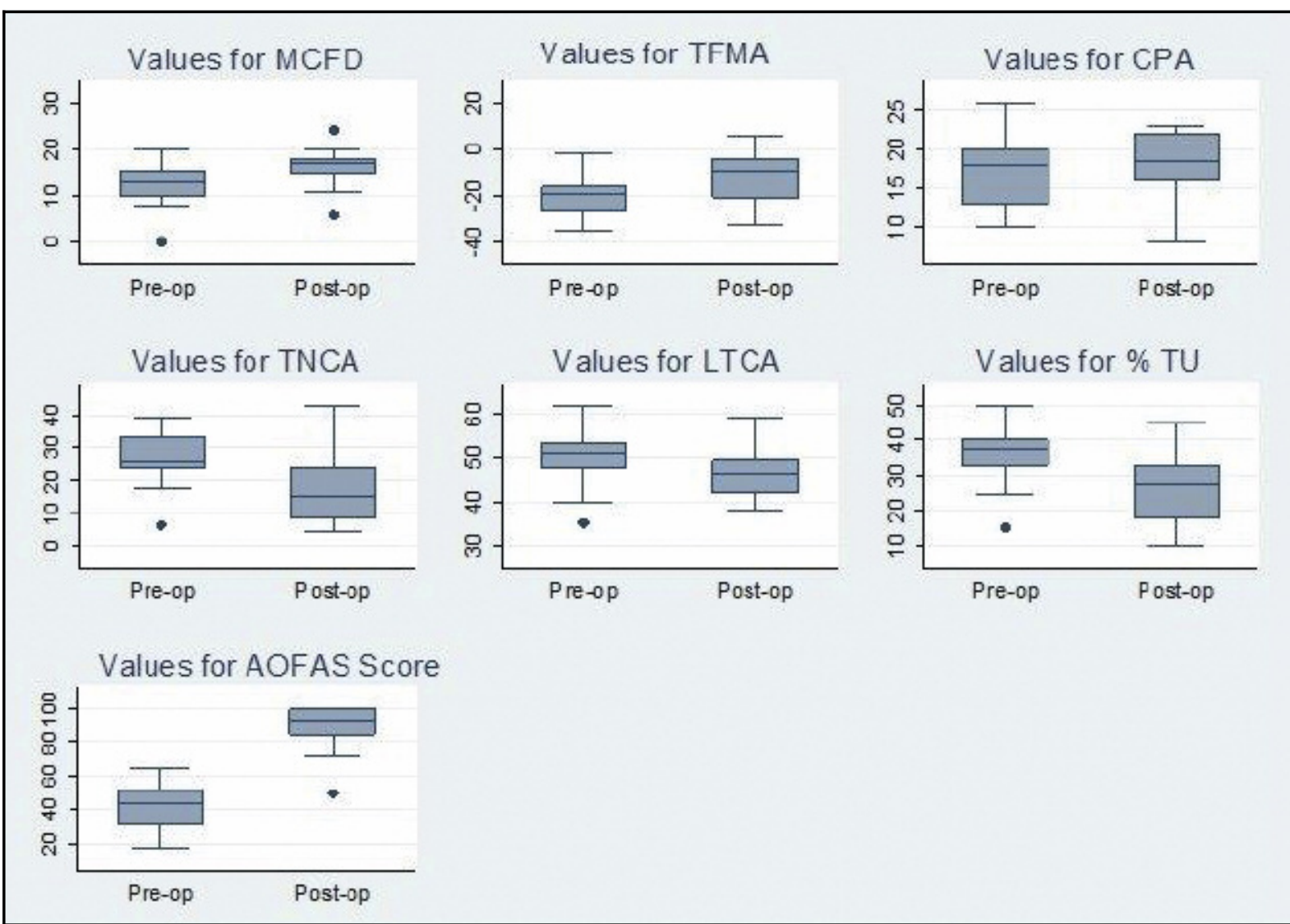


There was a decrease in the mean values from pre-op to post-op for TNCA, LTCA and \% TU; these results are statistically significant for TNCA and \% TU, for LTCA the difference is slight and is not statistically significant. The data is further described in the box graphs, which compare median (IQR) of each set of matched values (Figure 14).

Two patients had a lateral column lengthening (50\% uncoverage of the talar head pre-operatively).

No patients had a gastrocnemius recession.

No patients had a Cotton procedure.

\section{Complications}

There were no wound complications.

One patient had delayed union of the calcaneal tuberosity (radiologic union at three months).

One patient took four months for the lateral column lengthening to unite (with fixatives failure - broken staple).

Thirty per cent of patients had transient numbness of the lateral heel. This became apparent only with direct questioning.

There were no DVTs.

\section{Discussion}

Multiple procedures have been described for the management of stage II PTT dysfunction. Initially, arthrodesis, either triple or double was the treatment of choice.

Joint-preserving procedures have evolved over recent years and a combination of soft tissue and bone procedures are now preferred ${ }^{34}$ yielding statistically significant improvement in the deformity, pain and function. ${ }^{3441}$

We present a series of 20 patients with stage II PTT dysfunction who underwent the joint-preserving procedures.

These patients were followed up prospectively for one year. All patients were satisfied with respect to pain relief and functional outcome. Only two patients considered reoperation for residual deformity.

During the period of study no patient was converted to a fusion.

This re-enforces the dictum 'treat the patient and not the X-ray'. The individual procedures are technically demanding and should be carried out with good pre-operative planning and a solid foundation of the anatomy and aim of each individual procedure. It should not be undertaken by the occasional foot surgeon and a certain amount of training and expertise is required.

Since the above study, we are more prone towards gastrocnemius recessions and lateral column lengthening. ${ }^{35}$

\section{Conclusion}

In the surgical treatment of AAFF deformity due to stage II PTT, joint-preserving surgery which includes a combination of soft tissue and bone procedures, is preferred.
Most of these reconstructive procedures include a FDL tendon transfer and a calcaneal osteotomy with varying other components as required.

Our prospective study yielded a high patient satisfaction rate and minimal complications.

We found that there is no correlation between general patient satisfaction and residual deformity. Most of the radiographic parameters improved significantly so did the AOFAS score.

Although rehabilitation is lengthy, the procedure is functionally superior to arthrodesis of non-arthritic hindfoot joints.

\section{Conflict of interest statement}

The content of this article is the original work of the authors. No benefits of any form have been received or will be received from a commercial party related directly or indirectly to the subject of this article.

\section{References}

1. Iossi M, Johnson JE, McCormick JJ, Klein SE. Short term radiographic analysis of operative correction of adult acquired flatfoot deformity. Foot Ankle Int. 2013; 34(6):781-91.

2. Mann RA. Acquired flatfoot in adults. Clin Orthop Rel Res. 1983;181:46-51.

3. Johnson KA. Tibialis posterior tendon rupture. Clin Orthop Rel Res. 1983;177:140-47.

4. Kulowski J. Tendovaginitis (tenosynovitis): general discussion and report of one case involving the posterior tibial tendon. Missouri State Med Assoc. 1936;33:135-37.

5. Deland JT, de Asla RJ, Sung IH, Ernberg LA, Potter HG. Posterior tibial tendon insufficiency: which ligaments are involved. Foot Ankle Int. 2005;26(6):427-35.

6. Myerson MS. Adult acquired flatfoot deformity J Bone Joint Surg. 1996;78A:780-92.

7. Aronow MS. Tendon transfer options in managing the adult flexible flatfoot. Foot Ankle Clinics. 2012;17(2):205-26.

8. Deland JT. Adult acquired flatfoot deformity. J Am Acad Orthop Surg. 2008;16:399-406.

9. Guha AR, Perera AM. Calcaneal osteotomy in the treatment of adult acquired flatfoot deformity. Foot Ankle Clinics. 2012;17(2):247-58.

10. Kohls-Gatzoulis J, Woods B, Angel JC, Singh D. The prevalence of symptomatic posterior tibialis tendon dysfunction in women over the age of 40 in England. J Foot Ankle Surg. 2009;15:75-81.

11. Fuhrmann RA, Trommer T, Venbrocks RA. The acquired buckling flat foot. A foot deformity due to obesity? Orthopaed. 2005;34:682-99.

12. Mann RA, Thompson FM. Rupture of the posterior tibial tendon causing flat foot. Surgical treatment. J Bone Joint Surg Am. 1985;67:556-61.

13. Funk DA, Cass JR, Johnson KA. Acquired adult flat foot secondary to posterior tibial tendon pathology. J Bone Joint Surg Am. 1986;68:95-102.

14. Kohls-Gatzoulis JA, Singh D. Tibialis posterior dysfunction as a cause of flatfeet in elderly patients. Foot. 2004;14:207209. 
15. Holmes GBII, Mann RA. Possible epidemiological factors associated with rupture of the posterior tibial tendon. Foot Ankle. 1992;13:70-79.

16. Pomeroy GC, Pike RH, Beals TC, Manoli AII. Current concepts review. Acquired flatfoot in adults due to dysfunction of the posterior tibial tendon. J Bone Joint Surg. 1999;81A:1173-82.

17. Henceforth WD, 2nd, Deyerle WM. The acquired unilateral flatfoot in the adult: Some causative factors. Foot Ankle. 1982;2:304-308.

18. Kohls-Gatzoulis JA, Angel JC, Singh D, Haddad F, Livingstone J, Berry G. Tibialis posterior dysfunction: a common and treatable cause of adult acquired flatfoot. $B M J$. 2004;329(7478):1328-33.

19. Myerson M, Solomon G, Shereff M. Posterior tibial tendon dysfunction. Its association with seronegative inflammatory disease. Foot Ankle. 1989;9:219-25.

20. Mosier SM, Pomeroy G, Manoli AII. Pathoanatomy and aetiology of posterior tibial tendon dysfunction. Clin Orthop Rel Res. 1999;365:12-22.

21. Dyal CM, Feder J, Deland JT, Thompson FM. Pes planus in patients with posterior tibial tendon insufficiency: asymptomatic versus symptomatic foot. Foot Ankle Int. 1997;18:85-88.

22. Kohls-Gatzoulis JA, Singh D, Angel JC. Tibialis posterior insufficiency occurring in a patient without peroneii: a mechanical aetiology. Foot Ankle Int. 2001;22:950-52.

23. Mann RA, Thompson FM. Rupture of the posterior tibial tendon causing flatfoot. J Bone Joint Surg 1985;67A:556-61.

24. Yeap JS, Singh D, Birch R. Tibialis posterior tendon dysfunction: a primary or secondary problem? Foot Ankle Int. 2001;22:51-55.

25. Mizel MS, Temple HT, Scranton PE II, Gellman RE, Hecht PJ, Horton GA, et al. Role of the peroneal tendons in the production of the deformed foot with posterior tibial tendon deficiency. Foot Ankle Int. 1999;20:285-89.

26. Johnson KA, Strom DE. Tibialis posterior tendon dysfunction. Clin Orthop Rel Res. 1989;239:196-206.

27. Raikin SM, Winters BS, Daniel JN. The RAM Classification. Foot Ankle Clinics. 2012;17(2):169-81.

28. Pomeroy GC, Pike RH, Beals TC, Manoli AII. Acquired flatfoot in adults due to dysfunction of the posterior tibial tendon. J Bone Joint Surg Am. 1999;81:1173-82.

29. Bluman EM, Title CI, Myerson MS. Posterior tibial tendon rupture: a refined classification system. Foot Ankle Clinics. 2007;12:233-49.
30. Vulcano E, Deland JT, Ellis SJ. Approach and treatment of the adult acquired flatfoot deformity. Curr Rev Musculoskelet Med. 2013;6(4):294-303.

31. Mehta SK, Kellum RB, Robertson GH, Moore AR, Wingerter SA, Tarquino TA. Radiographic correction of stage III posterior tibial tendon dysfunction with a modified triple arthrodesis. Foot Ankle Int. 2013;34(10):1355-63.

32. Arangio GA, Wasser $T$, Rogman A. Radiographic comparison of standing medial cuneiform arch height in adults with and without acquired flat foot deformity. Foot Ankle Int. 2006;27(8):636-38.

33. Saragas NP, Ferrao PNF, Saragas E, Jacobson BF. The impact of risk assessment on the implementation of venous thromboembolism prophylaxis in foot and ankle surgery. Foot Ankle Surg. 2014;20:85-89.

34. Hiller L, Pinney SJ. Surgical treatment of acquired flatfoot deformity. What is the state of practice among academic foot and ankle surgeons in 2002? Foot Ankle Int. 2003;24(9):701705.

35. Silva MGAN, Tan SHS, Chong HC, Su HCD, Singh IR. Results of operative correction of grade IIB tibialis posterior tendon dysfunction. Foot Ankle Int. 2015;36(2):165-71.

36. El-Tayeby HM. The severe flexible flatfoot: a combined reconstructive procedure with re-routing of the tibialis anterior tendon. J Foot Ankle Surg. 1999;38(1):41-49.

37. Guyton GP. Flexor digitorum longus transfer and medial displacement calcaneal osteotomy for posterior tibial tendon dysfunction: a middle term clinical follow-up. Foot Ankle Int. 2001;22(8):627-32.

38. Knupp MHB. The Cobb procedure for treatment of acquired flatfoot deformity associated with stage II insufficiency of the posterior tibial tendon. Foot Ankle Int. 2007;28(4):416-21.

39. Myerson MS. Treatment of stage II posterior tibial tendon deficiency with flexor digitorum longus tendon transfer and calcaneal osteotomy. Foot Ankle Int. 2004;25(7):445-50.

40. Parsons S. Correction and prevention of deformity in type II tibialis posterior dysfunction. Clin Orthop Relat Res. 2010;468(4):1025-32.

41. Zaw H, Calder JD. Operative management options for symptomatic flexible adult acquired flatfoot deformity: a review. Knee Surg Sports Traumatol Arthrosc. 2010;18:135-42.

This article is also available online on the SAOA website (www.saoa.org.za) and the SciELO website (www.scielo.org.za). Follow the directions on the Contents page of this journal to access it. 